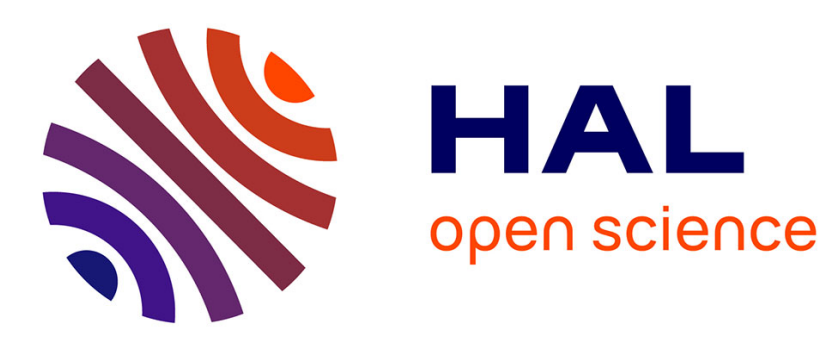

\title{
Learning Evaluation Using Non-classical Logics
}

Genivaldo Carlos Silva, Jair Minoro Abe

\section{To cite this version:}

Genivaldo Carlos Silva, Jair Minoro Abe. Learning Evaluation Using Non-classical Logics. IFIP International Conference on Advances in Production Management Systems (APMS), Sep 2015, Tokyo, Japan. pp.558-564, 10.1007/978-3-319-22756-6_68 . hal-01417613

\section{HAL Id: hal-01417613 \\ https://hal.science/hal-01417613}

Submitted on 15 Dec 2016

HAL is a multi-disciplinary open access archive for the deposit and dissemination of scientific research documents, whether they are published or not. The documents may come from teaching and research institutions in France or abroad, or from public or private research centers.
L'archive ouverte pluridisciplinaire HAL, est destinée au dépôt et à la diffusion de documents scientifiques de niveau recherche, publiés ou non, émanant des établissements d'enseignement et de recherche français ou étrangers, des laboratoires publics ou privés. 


\title{
Learning evaluation using non-classical logics
}

\author{
Genivaldo Carlos Silva ${ }^{1}$, Jair Minoro Abe ${ }^{1}$ \\ ${ }^{1}$ Graduate Program in Production Engineering Paulista University \\ Rua Dr. Bacelar 1212 CEP 04026-002 - São Paulo - SP - Brazil \\ \{gcsilva@ig.com.br, jairabe@uol.com.br\}
}

\begin{abstract}
Among the various existing methods used in teachers' evaluation, one of the most used is the survey of the students themselves. This method may have incomplete (paracompleteness), conflicting or inaccurate results as they often deal often with subjective and contradictory opinions. This work presents a case study using a non-classical logic, to analyze these conflicting views. The Paraconsistent Annotated Evidential E $\tau$ Logic proves to be helpful in the analysis of these data types in order to see more clearly the items that should be improved.
\end{abstract}

Keywords: Paraconsistency, non-classic logics, teacher evaluation

\section{Introduction}

Several countries have intensely discussed more efficient ways to analyze the performance of teachers in an institution so they can provide the best possible learning to their students.

According to Derrington [1] the function of the director of the institution remains a key component in the evaluation of teachers, but a more comprehensive evaluation model incorporating a greater body of evidence will produce a more accurate view of teachers' skills. There are many other methods, including the self-reflection of teachers, student performance data and feedback from students. Concerning on feedback from students, one of the methods is the survey of the opinions themselves.

adfa, p. 1, 2011.

(C) Springer-Verlag Berlin Heidelberg 2011 
This research is a case study that uses a mathematical approach by evidential E $\tau$ paraconsistent logic, applied to the analysis of the results of research conducted with students in teachers' evaluation. It is expected, in this research, that the results obtained can give a clearer view of the relevance of the analyzed items, as well as its importance in the general context of assessment, showing those items that need to be improved.

\section{$2 \quad$ Background}

Abrami [2] shows that this model should not only include the evaluation of all teacher assignments, but also incorporate the socioeconomic and cultural context in which the professional works.

Fenwick [3] discusses the process, often difficult to assess the effectiveness of teaching in terms of student learning outcomes and suggests approaches to micro and macro level evaluation of teachers using student outcomes.

According to LaFee [4], students are very close to their teachers and are in a good position to assess their activities in room and know what works or not in their learning. According to Ferguson [5] even in developed countries like the USA, the school system is developed in some respects and underdeveloped in others. The main reasons for this underdevelopment are structural gaps and systemic inefficiencies in the education system to prepare young people for employment.

Rosenshine and Furst [6] identified some factors that influence learning, such as clarity, teacher orientation tasks, student involvement, among others.

The project "The Measure of Effective Teaching [7] - founded by the Bill \& Melinda Gates - studying methods that provide a more effective learning and among the elements used in the project is a survey of a dozen thousands of students who answer questions about their experiences on education. The results of the survey were used as one of the evaluation tools and feedback to teachers. However, this method may have incomplete, conflicting and inaccurate data, and risk evaluate metrics that have little to do with the really important behaviors of teachers face to educational goals due to because it is subjective opinions. DE MELO [8]

Abe [9] presents some aspects of paraconsistent systems and its applications in various fields. 


\subsection{Paraconsistent, Paracomplete and Non-alethic Logics}

In what follows, we sketch the non-classical logics discussed in the paper, establishing some conventions and definitions. Let $T$ be a theory whose underlying logic is $L$. $T$ is called inconsistent when it contains theorems of the form $A$ and $\neg A$ (the negation of $A$ ). If $T$ is not inconsistent, it is called consistent. $T$ is said to be trivial if all formulas of the language of $T$ are also theorems of $T$. Otherwise, $T$ is called non-trivial.

When $L$ is classical logic (or one of several others, such as intuitionistic logic), $T$ is inconsistent if $T$ is trivial. So, in trivial theories the extensions of the concepts of formula and theorem coincide. A paraconsistent logic is a logic that can be used as the basis for inconsistent but non-trivial theories.

A theory is called paraconsistent if its underlying logic is a paraconsistent logic. Many logicians have appreciated issues such as those described above. In 1910, the Russian logician Nikolaj A. Vasil'év (1880-1940) and the Polish logician Jan Lukasiewicz (1878-1956) independently glimpsed the possibility of developing such logics. Nevertheless, Stanislaw Jaskowski (1996-1965) was in 1948 effectively the first logician to develop a paraconsistent system, at the propositional level.

His system is known as 'discussive' (or discursive) propositional calculus. Independently, some years later, the Brazilian logician Newton C.A. da Costa (1929-) constructed for the first time hierarchies of paraconsistent propositional calculi $C_{\mathrm{i}}, 1$ $\leq i \leq \omega$ of paraconsistent first-order predicate calculi (with and without equality), of paraconsistent description calculi, and paraconsistent higher-order logics (systems $N F_{\mathrm{i}}, 1$ $\leq i \leq \omega)$. Another important class of non-classical logics are the paracomplete logics.

A logical system is called paracomplete if it can function as the underlying logic of theories in which there are formulas such that these formulas and their negations are simultaneously false. Intuitionistic logic and several systems of many-valued logics are paracomplete in this sense (and the dual of intuitionistic logic, Brouwerian logic, is therefore paraconsistent).

Consequently, paraconsistent theories do not satisfy the principle of non-contradiction, which can be stated as follows: of two contradictory propositions, i.e. one of which is the negation of the other, one must be false. In addition, paracomplete theories do not satisfy the principle of the excluded middle, formulated in the following form: of two contradictory propositions, one must be true. Finally, logics that are simultaneously paraconsistent and paracomplete are called non-alethic logics. 


\section{$3 \quad$ Methodology}

According to Rosenshine and Furst [6] and the report Student Perception Surveys and Their Implementation [7], a set of factors ( $\mathrm{Sn}$ ) was extracted, which constituted the research with students. The factors chosen were Attention, Control, Plainness, Knowledge, Magnetism, Checking and Reinforcement. Each factor has five statements, which shall be assigned grades from 0 to 10 for both possibilities, "Acceptance" and "Rejection", representing respectively the Belief and Disbelief levels for each statement. The results were analyzed according to Paraconsistent Logic Annotated Evidential E $\tau$ and presented in graphs using the paraanalizer algorithm according Da Silva Filho[10] and compared according to figure 1.

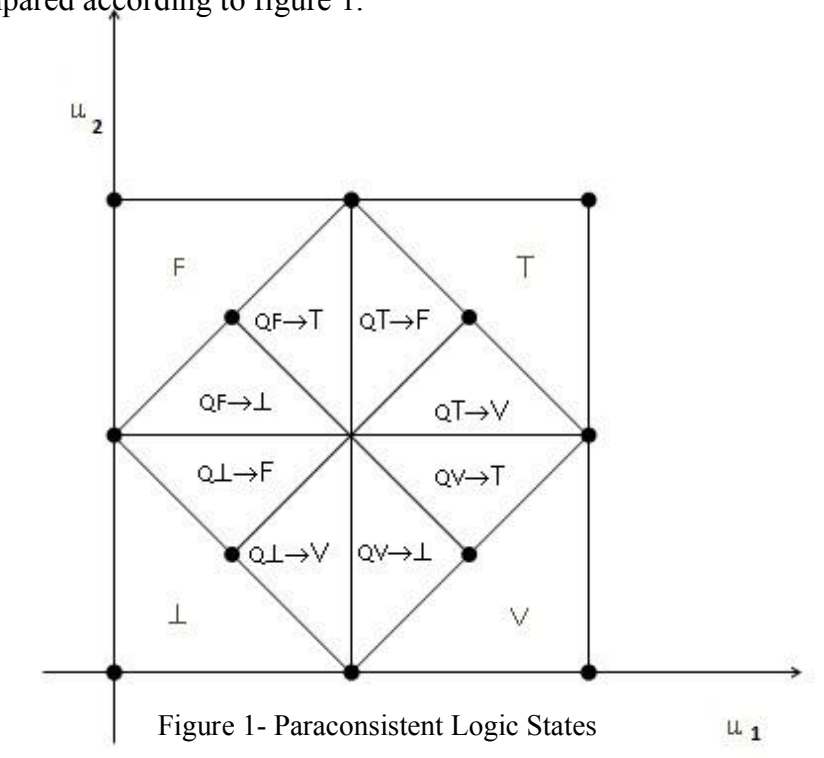

Where:

Falsity

Truth

F

Inconsistency

V

Paracompleteness

$\mathrm{T}$

Quasi-falsity tending to paracompleteness

$\perp$

Quasi-falsity tending to inconsistency

$\mathrm{QF} \rightarrow \perp$

Quasi-paracompleteness tending to falsity

$\mathrm{QF} \rightarrow \mathrm{T}$

Quasi-paracompleteness tendendo truth

$\mathrm{Q} \perp \rightarrow \mathrm{F}$

Quasi-inconsistency tending to truth

$\mathrm{Q} \perp \rightarrow \mathrm{V}$

$\mathrm{QT} \rightarrow \mathrm{V}$

Quasi-inconsistency tending to falsity

QT $\rightarrow$ F

Quasi-truth tending to paracompleteness

$\mathrm{QV} \rightarrow \perp$

Quasi-truth tending to inconsistency

$\mathrm{QV} \rightarrow \mathrm{T}$ 
Figure 2 shows the table with the data for the operational research group, with the same methodology used for B and C groups.

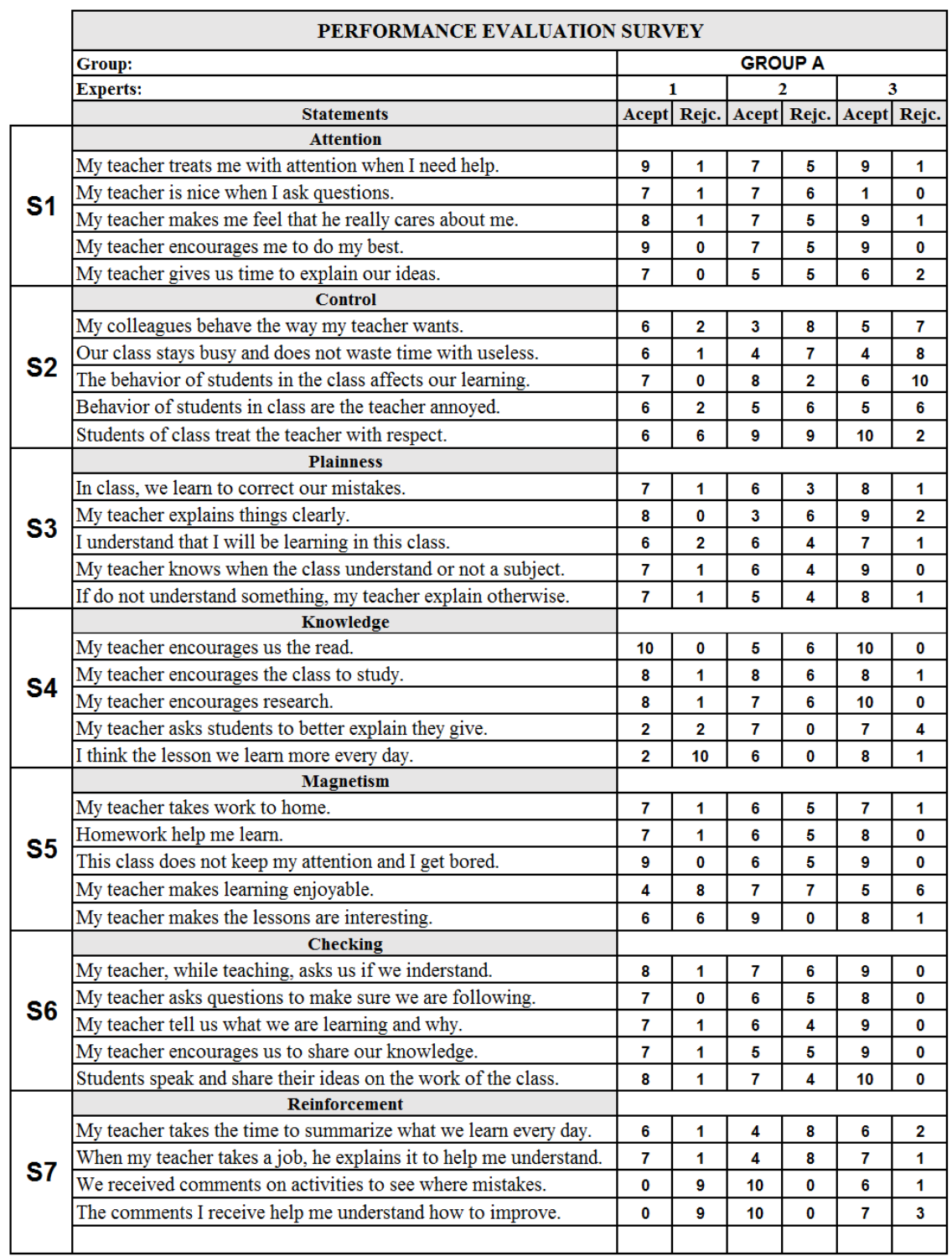

Figure 2 - Operational research data - Group A 


\subsection{Data Analysis}

In Figure 3, we have the result of the paraanalyzer algorithm analysis that shows that factors S1, S3 and S6 Attention - Plainness - Checking respectively, are considered viable, which means that they have been evaluated and do not require improvements.

On the other hand, we see that the factors S2, S4, S5 and S7 were considered inconclusive, it means, the information is not enough to lead to a decision on the items evaluated and eventually would require some improvement to achieve better evaluation levels.

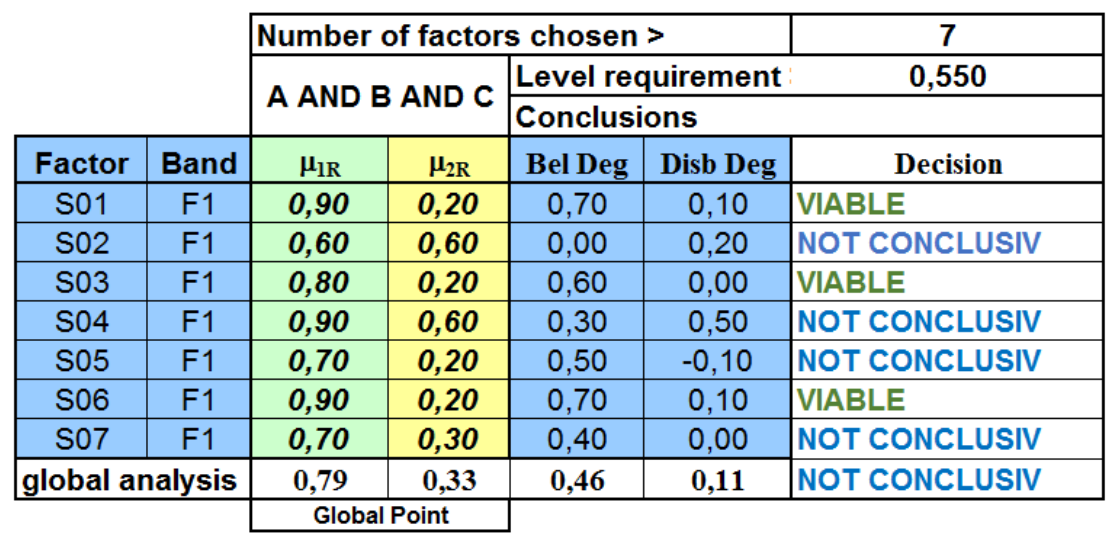

Figure 3 - Features Analysis Table

\section{$4 \quad$ Outcomes of Logic E $\tau$}

Figure 4 shows the result of global analysis, located on the near Quasi-truth tending to inconsistency area in the Square Unit of the Cartesian plan (SUCP), which indicates that some factors need to be improved in order to have a better assessment of the teacher. 


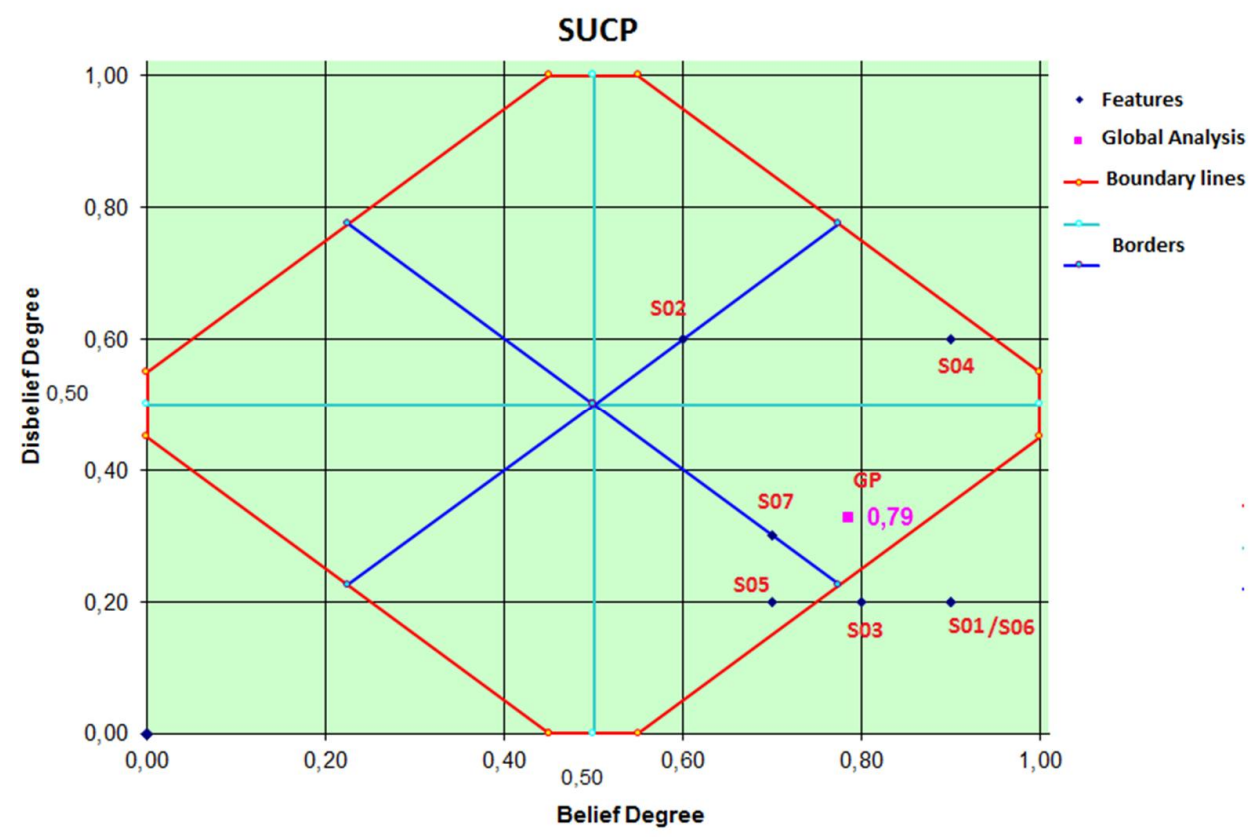

Figure 4 - Features Analysis with Logic States Graphic

\section{Conclusion}

The study achieved its goal in order to provide a tool to assess a group opinion. They may be contradictory, considering the weight of each opinion from the many experts, which in this case study are students of an institution. With this tool it is possible to identify features that can and should be improved.

This analysis can also be applied in all types of educational institutions and companies in which they have conflicting information for decision-making.

\section{REFERENCES}

1. Derrington, M.L.: Changes in Teacher Evaluation: Implications for the Principal's Work. Delta Kappa Gamma Bulletin. 77, 51-54 (2011).

2. Abrami, P.C.: How should we use student ratings to evaluate teaching? Research in Higher Education. 30, 221-227 (1989). 
3. Fenwick, T.J.: Using student outcomes to evaluate teaching: A cautious exploration. New directions for teaching and learning. 2001, 63-74 (2001).

4. LaFEE, S.: Students Evaluating Teachers. Education Digest. 80, 4-10 (2014).

5. Ferguson, R.F., Danielson, C.: How Framework for Teaching and Tripod 7Cs Evidence Distinguish Key Components of Effective Teaching. Designing Teacher Evaluation Systems: New Guidance from the Measures of Effective Teaching Project. (2014).

6. Rosenshine, B., Furst, N.: Research on teacher performance criteria. Research in teacher education. 37-72 (1971).

7. Policy and Practice Brief. "Asking about Teaching Students, Student Perception Surveys and Their Implementation", Bill \& Melinda Gates Foundation, 2012; PDF document at the address http://www.metproject.org/downloads/Asking_Students_Practitioner_Brief.pdf.

8. De Mello, G.N.: Observação da interação professor-aluno: uma revisão crítica. Cadernos de Pesquisa. 19-28 (2013).

9. Abe, J.M., Paraconsistent Artificial Neural Networks: an Introduction, Lecture Notes In Computer Science 3214, Springer, 942-948 (2004)

10. Da Silva Filho, J.I., Torres, G.L., Abe, J.M.: Uncertainty Treatment Using Paraconsistent Logic - Introducing Paraconsistent Artificial Neural (2010) 